\title{
The Effect of Spacecraft Simulated Condition on Serum Leptin in Rats
}

\author{
Iraj Mirzaii- Dizgah ${ }^{1,}{ }^{*}$, Mohammad-Masoud Andalib ${ }^{2}$, Alireza Andalib ${ }^{3}$, Mohammad-Reza \\ Mirzaii-Dizgah ${ }^{4}$ and Mohammad-Hosein Mirzaii-Dizgah ${ }^{5}$ \\ ${ }^{1}$ Department of Physiology, AJA University of Medical Sciences, Tehran, Iran \\ ${ }^{2}$ School of Architecture, Isfahan University of Art, Isfahan, Iran \\ ${ }^{3}$ Science and Research Branch, Islamic Azad University, Tehran, Iran \\ ${ }^{4}$ School of Medicine, Iran University of Medical Sciences, Tehran, Iran \\ ${ }^{5}$ Department of Physiology, Faculty of Medicine, AJA University of Medical Sciences, Tehran, Iran \\ "Corresponding author: AJA University of Medical Sciences, Tehran, Iran. Tel: +98-9122856911, Email: emirzaii@alumnus.tums.ac.ir
}

Received 2018 April 27; Revised 2018 July 24; Accepted 2018 July 25.

\begin{abstract}
Objectives: Physiological changes in spacecraft situation (endurance of gravity and circadian rhythm changes) can alter the neuromodulator. The objective of the current study was to determine the effects of 14 days of simulated microgravity and alteration of circadian rhythm (as simulated spacecraft situation) on the serum leptin level in rats.

Methods: 32 male Wistar rats were divided into four groups (free motion groups with 12/12 hours or 45/45 minutes dark/light cycles and unloading tail suspension condition groups with 12/12 hours or 45/45 dark/light cycles). The serum leptin level was analyzed 14 days after the beginning of the intervention by ELISA. Data were analyzed by the two-way ANOVA.

Results: The data showed that the unloading situation significantly increased the serum leptin level. However, light/dark changing cycles had no significant effect on the serum leptin level.

Conclusions: It seems that the unloading situations were much more effective than the light/dark changing cycles on the serum leptin level.
\end{abstract}

Keywords: Leptin, Circadian rhythm, Tail suspension, Microgravity

\section{Background}

Spacecraft can turn the earth in about 90 minutes. Therefore, astronauts experience both microgravity and 45/45 minutes light/dark cycles. Leptin mainly is synthesized in both white and brown adipose tissues. It has been shown that the level of serum leptin level increases markedly in obese humans and animals (1). It has been indicated that continued strength exercise, such as marathon running, decreases leptin concentration (2). Nevertheless, other studies have revealed that moderateintensity aerobic exercise and acute or chronic exercise in men and women do not affect the leptin levels $(1,3)$. The experiment shows that fast reductions in leptin concentrations in response to the restriction of energy or fasting seem to be greater than the decrease in fat mass in both rodent and humans (4). Therefore, it has speculated that leptin may be a sensor for energy stores in short-term changes (5).

It has been shown mice treated with leptin lose more weight suggesting that leptin also increases energy expenditure (6). Leptin acts by binding to special receptors
(obRs) expressed in CNC as well as in peripheral tissues (7, $8)$. The most important roles of leptin are including regulation of energy homeostasis, neuroendocrine function, and metabolism evaluation in human and animals. In addition, the leptin in plasma is an energy reserve and adjusts food intake and energy expenditure controlled by signals through the central nervous system $(7,9)$. Brown adipose tissue thermogenesis is activated and sympathetic nerve activity is augmented by leptin in mice. The administration of leptin in the long-term could result in the rewinding of the connections among hypothalamic neurons or promoting synaptic plasticity $(1,10)$.

In order to simulate a microgravity situation in rats, tail-suspension model has been recommended by the national aeronautics and space administration and therefore, has been widely used. The rats were hanged at an angle of $30^{\circ}$. The tail of the rats was connected to a flexible cable that was attached to the ceiling of the cage, allowing the rats to move $360^{\circ}$ and to access water and food throughout the experimental period (11). It is speculated that microgravity environment and alteration in the light/dark period could cause changes in the physi- 
ology of rodents, which affected the hormone secretion, circadian rhythms, food intake, and so on. We hypothesized that alteration in life rhythms, microgravity environment, and the stress tolerance due to changing the life condition could be reflected in the hormone levels and energy metabolism. Therefore, the alterations in leptin level, as well as animal weight, were thought to assess in rats by changing the living conditions under the experimental conditions. Since food intake, energy expenditure, metabolic activity, and body weight are associated with hormones and neuro-mediators, an effective physiological change, for example, due to circadian rhythm and hypergravity change, would be considered to indicate the effect of alterations in situations. Therefore, the purpose of the present study was to determine the effects of 14 days of simulated microgravity and alteration of circadian rhythm (simulated spacecraft situation) on the serum leptin level in rats.

\section{Methods}

The study was in agreement with the guidelines of the national institute of health guide for the care and use of laboratory animals (NIH publications no. 80 - 23).

32 Wistar male rats were randomly divided into four equal groups: free motion groups with 12/12 hours or 45/45 minutes dark/light cycles and unloading tail suspension condition groups with 12/12 hours or $45 / 45$ dark/light cycles $(12,13)$. The rats were maintained at $23 \pm 2{ }^{\circ} \mathrm{C}$ and food and distilled water were provided ad libitum.

The tail-suspension technique described previously by Morey-Holton and Globus (14) was used to elicit the effects of simulated microgravity. Briefly, the tail of each rat was cleaned, dried, and wrapped in adhesive plaster. The hind limbs of the rats were unloaded by suspending the tail at a $30^{\circ}$ head down angle in order to avoid contact of the hind limbs with the ground. The animals were free to move on their forelimbs and had free access to food and water. All tail-suspended rats were kept in this state of unloading of the hind limbs and individually housed in a cage for 14 days.

On day 15 , the rats were anesthetized with a combination of $80 \mathrm{mg} / \mathrm{kg}$ ketamine and $5 \mathrm{mg} / \mathrm{kg}$ xylazine; then blood samples were obtained from the heart collected in 10 $\mathrm{mL}$ glass vacuum tubes without additive, permitted to clot and centrifuged (2000 g, 10 minutes); finally, the serum was separated. The specimens were stored at $-70^{\circ} \mathrm{C}$ for the subsequent determination of leptin concentration.

The leptin concentration was assayed by ELISA technology using commercially available kits (Eastbiopharm, Torrance, USA). The experiments were performed according to the manufacturer instruction.
The data were analyzed by the two-way ANOVA (SPSS software), followed by the Bonferroni post hoc test. Differences were considered significant at $\mathrm{P}<0.05$. The data were expressed as means \pm SEM.

\section{Results}

The effect of simulated spacecraft condition on the mean serum leptin levels in rats is summarized in Table 1. The mean serum leptin level was altered by spacecraft simulated condition $(\mathrm{P}<0.05)$ (Figure 1$)$. The post-hoc analysis indicated that the level of serum leptin significantly increased in the unloading (microgravity) condition as compared with the free motion groups $(\mathrm{P}<0.05)$. However, there were no significant differences in the serum leptin level between 45/45 light/dark and 12/12 light/dark rhythm situations $(\mathrm{P}>0.05)$.

Table 1. The Effect of Simulated Spacecraft Condition on the Mean ( \pm SEM) Serum Leptin (ng/mL) Levels in Rats

\begin{tabular}{lcc}
\hline & Free Motion & Unloading \\
\hline $\mathbf{1 2 / 1 2}$ hours light/dark rhythm & $1.63 \pm 0.13$ & $2.18 \pm 0.06$ \\
$\mathbf{4 5 / 4 5}$ minutes light/dark rhythm & $1.25 \pm 0.27$ & $2.45 \pm 0.05$ \\
\hline
\end{tabular}

\section{Discussion}

Alteration in living conditions such as microgravity and circadian rhythms, which occur in spacecraft, affects the physiological necessity parameters and life treating factors in astronauts. Exposure to microgravity could change physiological situations in space traveling, causing several neurologic changes in human or animal $(15,16)$. Recent studies have reported that increased gravity could increase brain permeability, ischemic and degenerated neurons in the cortex and hippocampus in rats $(17,18)$. In the present study, a rat animal model was used for the assessment of microgravity and alteration of light/dark cycle effects on leptin. Our results showed that tail suspension hindlimb unloading in rats as models to evaluate the microgravity effects could change neuromodulator of the leptin level.

The plasma leptin level principally reflects the amount of energy storage in adipose tissue and directs the CNS in regulating energy homeostasis, neuroendocrine function, and metabolism (8). Moreover, it has been reported that the plasma leptin concentration in fed mice is $1.32 \mathrm{ng} / \mathrm{mL}$ but its level would reduce in fasted animals (19). It has been suggested that an alteration in circadian rhythms (light/dark cycle) acts through the suprachiasmatic nucleus to decrease food intake, alter hormonal profile, and 


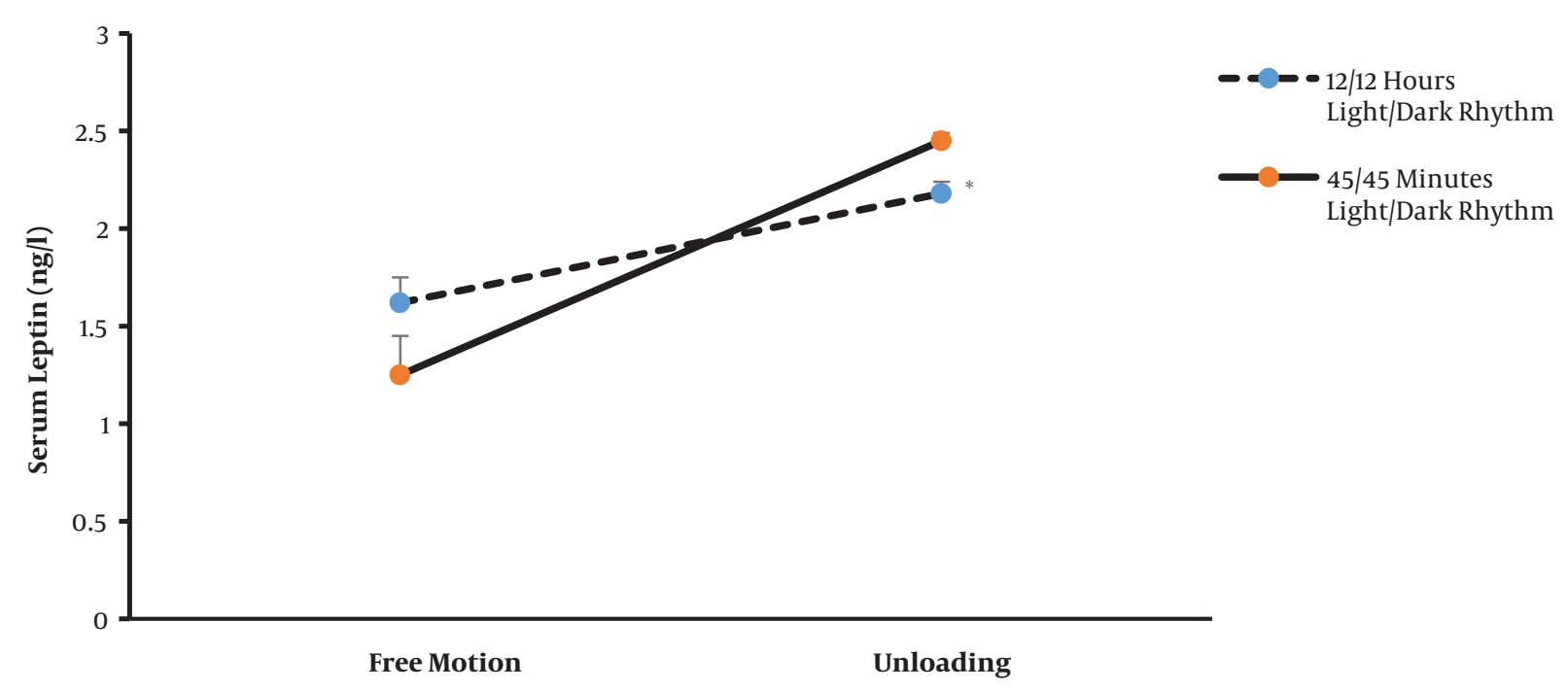

Figure 1. Effect of spacecraft simulated condition on serum leptin. Data are expressed as means \pm SEM. ${ }^{*}$ Different from the free motion group, $P<0.05$.

decrease anabolic hormones $(11,16,20)$. Our data revealed that even changing the light/dark cycle is unable to alter the leptin serum level in rats.

The serum leptin level was significantly higher in unloading rats. However, it has been shown that serum leptin decreases in unloading condition in food-restricted rats (21) while it is unchanged in head-down bed rest condition in human (22).

It has been shown that the plasma leptin level increases in both acute and chronic inflammation and its expression is regulated by pro-inflammatory mediators (23). On the other hand, astronauts experience brain and upper organs inflammation in microgravity condition, so it may be the possible mechanism of increasing leptin in our study in the unloading situation.

\subsection{Conclusion}

It seems that the unloading situations were much more effective than the light/dark changing cycles in the serum leptin level.

\section{References}

1. Margetic S, Gazzola C, Pegg GG, Hill RA. Leptin: a review of its peripheral actions and interactions. Int J Obes Relat Metab Disord. 2002;26(11):1407-33. doi:10.1038/sj.ijo.0802142. [PubMed:12439643].

2. Zaccaria M, Ermolao A, Brugin E, Bergamin M. Plasma leptin and energy expenditure during prolonged, moderate intensity, treadmill exercise. J Endocrinol Invest. 2013;36(6):396-401. doi: 10.3275/8656. [PubMed: 23095336].

3. Fedewa MV, Hathaway ED, Ward-Ritacco CL, Williams TD, Dobbs WC. The Effect of Chronic Exercise Training on Leptin: A Systematic Review and Meta-Analysis of Randomized Controlled Trials. Sports Med. 2018;48(6):1437-50. doi:10.1007/s40279-018-0897-1.
4. Boden G, Chen X, Mozzoli M, Ryan I. Effect of fasting on serum leptin in normal human subjects. J Clin Endocrinol Metab. 1996;81(9):3419-23. doi: 10.1210/jcem.81.9.8784108. [PubMed: 8784108].

5. Trayhurn P, Thomas ME, Duncan JS, Rayner DV. Effects of fasting and refeeding on ob gene expression in white adipose tissue of lean and obese (oblob) mice. FEBS Lett. 1995;368(3):488-90. [PubMed: 7635205].

6. Halaas JL, Gajiwala KS, Maffei M, Cohen SL, Chait BT, Rabinowitz D, et al. Weight-reducing effects of the plasma protein encoded by the obese gene. Science.1995;269(5223):543-6. [PubMed: 7624777].

7. Niswender KD, Morton GJ, Stearns WH, Rhodes CJ, Myers MG, Schwartz MW. Intracellular signalling. Key enzyme in leptininduced anorexia. Nature. 2001;413(6858):794-5. doi:10.1038/35101657. [PubMed: 11677594].

8. Kelesidis T, Kelesidis I, Chou S, Mantzoros CS. Narrative review: the role of leptin in human physiology: emerging clinical applications. Ann Intern Med. 2010;152(2):93-100. doi: 10.7326/00034819-152-2-201001190-00008. [PubMed: 20083828]. [PubMed Central: PMC2829242].

9. Chan JL, Bullen J, Stoyneva V, Depaoli AM, Addy C, Mantzoros CS. Recombinant methionyl human leptin administration to achieve high physiologic or pharmacologic leptin levels does not alter circulating inflammatory marker levels in humans with leptin sufficiency or excess. J Clin Endocrinol Metab. 2005;90(3):1618-24. doi: 10.1210/jc.20041921. [PubMed: 15613407$]$.

10. Scarpace PJ, Matheny M, Pollock BH, Tumer N. Leptin increases uncoupling protein expression and energy expenditure. Am J Physiol Endoc M.1997;273(1):E226-30. doi:10.1152/ajpendo.1997.273.1.E226.

11. Lew PS, Wong D, Yamaguchi T, Leckstrom A, Schwartz J, Dodd JG, et al. Tail suspension increases energy expenditure independently of the melanocortin system in mice. Can J Physiol Pharmacol. 2009;87(10):839-49. doi: 10.1139/Y09-074. [PubMed: 20052010].

12. Salehi MS, Mirzaii-Dizgah I, Vasaghi-Gharamaleki B, Zamiri MJ. Effect of hindlimb unloading on stereological parameters of the motor cortex and hippocampus in male rats. Neuroreport. 2016;27(16):1202-5. doi: 10.1097/WNR.0000000000000675. [PubMed: 27607230].

13. Mirzaii Dizgah I, Bagheri Chimeh P, Tavakoli Far B. Hindlimb Unloading Effects on $\beta$-Endorphin Receptor in Rats. Archiv Neurosci. 2018;In Press(In Press). doi: 10.5812/archneurosci.62975. 
14. Morey-Holton ER, Globus RK. Hindlimb unloading rodent model: technical aspects. J Appl Physiol (1985). 2002;92(4):1367-77. doi: 10.1152/japplphysiol.00969.2001. [PubMed: 11895999].

15. Fujii MD, Patten BM. Neurology of Microgravity and Space Travel. Neurol Clin. 1992;10(4):999-1013. doi: 10.1016/s0733-8619(18)30192-0.

16. Da Silva MS, Zimmerman PM, Meguid MM, Nandi J, Ohinata K, Xu Y, et al. Anorexia in space and possible etiologies: an overview. Nutrition. 2002;18(10):805-13. [PubMed: 12361771].

17. Sun XQ, Li JS, Cao XS, Wu XY. Compound mechanism hypothesis on+ $\mathrm{Gz}$ induced brain injury and dysfunction of learning and memory. The 9th European Symposium on Life Sciences Research in Space / 26th Annual International Gravitational Physiology Meeting. Cologne, Germany. 2005.

18. Scarpace PJ, Matheny M, Moore RL, Tumer N. Impaired leptin responsiveness in aged rats. Diabetes. 2000;49(3):431-5. [PubMed: 10868965].

19. Watanobe H, Habu S. Leptin regulates growth hormone-releasing factor, somatostatin, and alpha-melanocyte-stimulating hormone but not neuropeptide Y release in rat hypothalamus in vivo: relation with growth hormone secretion. J Neurosci. 2002;22(14):6265-71. [PubMed:
12122085].

20. Cvijic G, Janic-Sibalic V, Demajo M, Karakasevic A, Petrovic VM, Ivanisevic-Milovanovic OK. The effects of continuous light and darkness on the activity of monoamine oxidase A and B in the hypothalamus, ovaries and uterus of rats. Acta Physiol Hung. 1997;85(3):269-76. [PubMed: 10101541].

21. Baek K, Barlow AA, Allen MR, Bloomfield SA. Food restriction and simulated microgravity: effects on bone and serum leptin. J Appl Physiol (1985). 2008;104(4):1086-93. doi: 10.1152/japplphysiol.01209.2007. [PubMed: 18276897].

22. Kanikowska D, Sato M, Iwase S, Nishimura N, Shimizu Y, Inukai Y, et al. Leptin and ghrelin levels in humans during physical inactivity induced by head-down bed rest. Aviat Space Environ Med.2010;81(4):3836. [PubMed: 20377141].

23. Otero M, Lago R, Gomez R, Dieguez C, Lago F, Gomez-Reino J, et al. Towards a pro-inflammatory and immunomodulatory emerg ing role of leptin. Rheumatology (Oxford). 2006;45(8):944-50. doi: 10.1093/rheumatology/kel157. [PubMed:16720637]. 